\title{
63
}

\section{Collaboration Awareness and its Use to Consolidate a Disperse Group}

\author{
Tracy Narine, Andrea Leganchuk, Marilyn Mantei, William Buxton
}

\author{
University of Toronto \\ Dept. of Computer Science \\ 10 Kings College Road \\ Toronto, Ontario \\ CANADA M5S 1A4 \\ \{tracyn,andrea,mantei,willy\}@dgp.utoronto.ca
}

\begin{abstract}
Communication often drops dramatically between group members who move a significant distance from their work group despite the provision of mediated communication support. Although the poor quality of the communication exchange via mediated communication is certainly responsible for a significant portion of this drop, lowered suggestion, availability and comfortableness of the communication contact may also cause a drop. With the intent of re-creating these background contact characteristics found in a co-located group, low resolution video pictures of widely dispersed co-workers were exchanged and displayed on each others' workstations via a system called Postcards. The study found that all users (close and far) tended to use the system extensively for coordinating telephone calls and visits. Users also reported knowing more about what is happening at work and knowing more about their co-workers time pressures. They saw no change in the amount of telephone traffic, E-mail or informal meetings that took place. Thus, Postcards provided useful cues for contact coordination but did not affect the frequency of communication. Overall, the results suggest that the continued awareness of both the presence of one's co-workers and a knowledge of their contactability state are a useful part of maintaining distant contacts.
\end{abstract}

KEYWORDS Postcards, Portholes, Awareness, Video Desktop Conferencing, Media Spaces, Coordination, Collaboration

\section{INTRODUCTION}

When co-workers are not co-located, project deadlines slip, miscommunication is more common and optional projects never get carried out (Kraut \& Egido, 1988). In the modern world, the extensive amount of electronic communication possibilities suggest that distant work collaborations should not be a problem. This is especially true with the widespread use of the cellular phone, electronic mail and video conferencing. Researchers argue that this is because existing media are too limited. Media spaces were developed with the belief that a properly managed video exchange would encourage collaboration (Tang, Isaacs \& Rua, 1994). It has been difficult, however, to find much difference in the work performed when telephone is compared to

Human-Computer Interaction: INTERACT'97 S. Howard, J. Hammond \& G. Lindgaard (editors) Published by Chapman \& Hall CIFIP 1997 
video in experimental settings (Short, Williams \& Christie, 1976; Williams, 1977).

Hollan and Stornetta (1992) argue that communication systems differentiate co-located workers from distant workers because they fail to add the richness of face-toface communication. They further suggest that communication media can add value to communication only if they move away from attempting to be a poor second to face-to-face encounters. We agree with this approach and argue that one mechanism that could enhance both mediated and face-to-face communication is collaboration awareness.

We define collaboration awareness as one case of background awareness (Buxton, 1994; 1995) in which a co-worker is peripherally made aware of the potential for collaboration with a colleague. We use a variation of the Portholes system developed at Rank Xerox EuroPARC (Dourish \& Bly, 1992) called Postcards. Postcards, like Portholes, takes frequent low resolution video snapshots and broadcasts them via computer network for display on workstations. It is these updated pictures of co-workers which we believe make coworkers collaboratively aware.

\section{THE CASE FOR COLLABORATION AWARENESS}

In attempting to demonstrate what value collaboration awareness might have for co-workers, we need to explore why communication drops off so dramatically when colleagues are not co-located. Co-located workgroups engage in multiple forms of communication creating a social network (Scott, 1991). Consider a colocated workgroup that uses telephone, voice mail and E-mail extensively. If one or more group members moves to a new location that is non-proximal the communication links between these individuals and the rest of the network soon drop below a typical threshold. This is strange especially in light of Haythornthwaite et al's study (1995) which describes a co-located workgroup whose members had weakly overlapping work schedules but yet maintained strong contact through E-mail communications. These individuals were co-located in space but certainly not in time. One argument given for the drop in communication is a failure of the communication media to provide sufficient richness to the contact making contact with co-located colleagues preferable. We do not discount the studies that show that mediated communication is not as rich as face-to-face, but we suggest that the drop in communication may also be due to weak support for the intent to communicate.

We see this intent thwarted by three different mechanisms at play. They are the lack of:

$$
\begin{array}{ll}
\text { - } & \text { intent stimulus } \\
\text { - } & \text { intent opportunity }
\end{array}
$$

Intent stimulus is any event which triggers an intent to communicate. In the design rationale for the Cruiser system, this was a colleague walking down the hall and seeing someone available in their office for conversation (Root, 1988). This form of stimulus is self-reinforcing when workers are co-located, but dwindles when workers are distant because of the need to maintain the exchange of faxes, E-mail or phone calls to continue the stimulus. Once one of the parties involved travels or is extremely busy, the chain is broken and the contact dwindles. Even in the workgroup with widely diverse work times, scheduled meetings where attendance from all workshifts was required, tended to restart the communication exchange.

Intent opportunity is the probability of making a communication contact once the intent to communicate is formulated. In a group with electronic mail support, this opportunity is always there, but its use also depends on the information to be communicated. As an asynchronous medium, it lacks the spontaneity and immediacy of synchronous forms. A common example of thwarted intent opportunity is the frustration of playing telephone tag. In co-located environments, intent opportunity will be much higher because so many more opportunities for communication will exist. Even in the diverse time workgroup, individuals modified their schedules to increase opportunities for contact when needed.

Intent comfort is the sense of the social acceptability of making the communication contact. When people are co-located, they cannot help but have contacts in the hallway or lunchroom, all of which make the contact more natural and less intrusive. When people are not colocated, these easily enacted contacts go away and there is more of a social barrier for making the contact. In addition, there is less shared information to use as conversation starters. 
We argue that despite its lack of richness and depth, mediated communication might be used more extensively at a distance if a form of background awareness enhanced the three communication intents. We study Postcards usage to examine this possibility. We have not looked at a widely separate group for our study but at one that is slightly separated. Face-to-face communication in the organization studied requires walking either up or down or opening locked doors. Thus, we are eliminating any mediated characteristics of communication and looking at how Postcards affects the intent to communicate when the face-to-face communication has a large startup cost.

We expect the presence of the video snapshots to cause co-workers to think about others and thus, generate a communication exchange. If this is so, we should find an increase in telephone calls and visits with the installation of the system. We also expect the video snapshots to indicate the availability of the other person. Thus, once the intent to communicate is established, we should see the snapshots being used to ascertain if the communication can take place. We should also see the use of the sensing agent that is built into Postcards, which lets a person know when the person with whom communication is desired returns to their office.

Finally, people can use Postcards to observe their coworkers and learn more about them. If a group is already co-located, this would not seem to be necessary. Thus, if the group is using Postcards in this fashion, it suggests that it is a useful tool for increasing the comfort intent by providing an understanding of one's fellow workers and their work characteristics. There is a possible fourth form of collaboration awareness that we will call intent aggregation which we do not cover in this paper. Monge et al (1985) were able to predict optimal meeting times after studying four days of co-workers' organizational proximity. We view this intent as a correlation to intent opportunity.

\section{THE INSTALLATION}

In Postcards, we extend the concept of Porthole's awareness by characterizing three forms of awareness mechanisms that might be at play. Postcards has been built with additional tools to support these mechanisms. Having a good image of one's co-workers availability at all times provides intent stimulus. Providing a mechanism that maintains the intent to communicate despite a co-worker's temporary absence also supports intent stimulus. Providing contact tools for instantly initiating a contact and images to indicate the availability of the contact support intent opportunity. Intent opportunity is also supported by listing contact information through other media, e.g., E-mail address and fax and telephone numbers. Providing regularly updated images of co-workers supports intent comfort. The features Postcards provides are described in the following paragraphs.

\subsection{The Postcards Application}

The main window of the Postcards user interface is shown in Figure 1. Each image is a grayscale picture 104 pixels wide and 80 pixels high. We have intentionally kept the pictures small and unobtrusive to avoid invasions of privacy. Smaller pictures also save bandwidth and screen real-estate. We display the title and the time the snapshot was taken.

A user can select which pictures of others to view from any of many Postcards sites. A list indicates which pictures are available and which ones the user is currently receiving. Support for operations such as video or voice contact are provided if Postcards resides in a media space. User Information is provided, like phone number and E-mail address. Users can also turn their own picture taking on or off.

The Sense option is used to notify the user when activity is next "sensed" in the selected person's office. This option acts like a secretarial agent who lets the user know that a given person has returned to their office. When activity is noted, a dialog box appears on the user's screen. It will timeout and disappear after 20 seconds in case the user is not around. Sensing continues to function until canceled by the user.

Sensing uses a simple image differencer which compares the amount of pixels that have changed between the previous image and the most recently captured image. If the change is above a set threshold, a sensing alert is sent. 


\subsection{The Site and Participants of the Study}

The site chosen for this study was a high-tech company.

Eight individuals participated in the study. We have divided the study group into team and peripheral members. The team members form a close knit group of six individuals. The peripheral members are two individuals in the company who do not carry out the same work as the team but either performed support work for them or served as a liaison between them and the rest of the company.

The team is made up of a senior manager, a project manager and four workers. This team is dispersed within the company having offices on three separate floors. Figure 2 gives an approximate measure of this dispersal. Distances between offices are shown in number of footsteps, doors, locked doors and stairs. As Figure 2 illustrates, there is a mix of open and closed offices within the study group. Only the three managers have offices with doors. To travel between floors, security doors and doors into stairwells must be opened. Only two participants ( 1 team member, 1 peripheral) are within a line of sight of each other. Given the distributed nature of the group, the cost to initiate any face-to-face communication is high, not unlike that of distant group members.

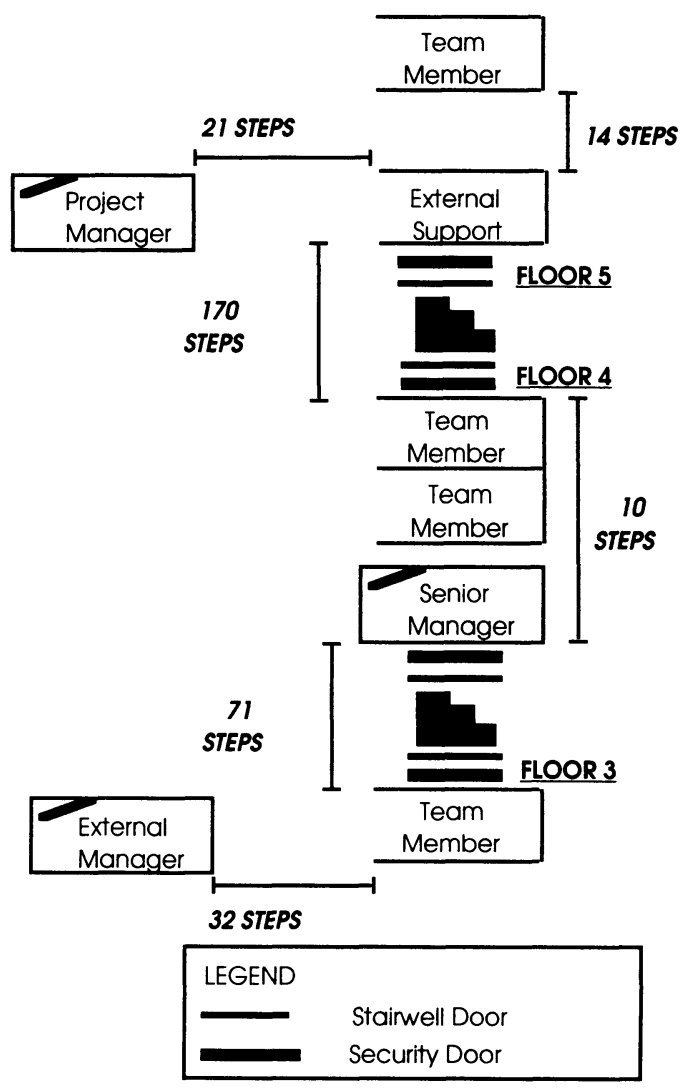

Figure 2: Footsteps between users in study group

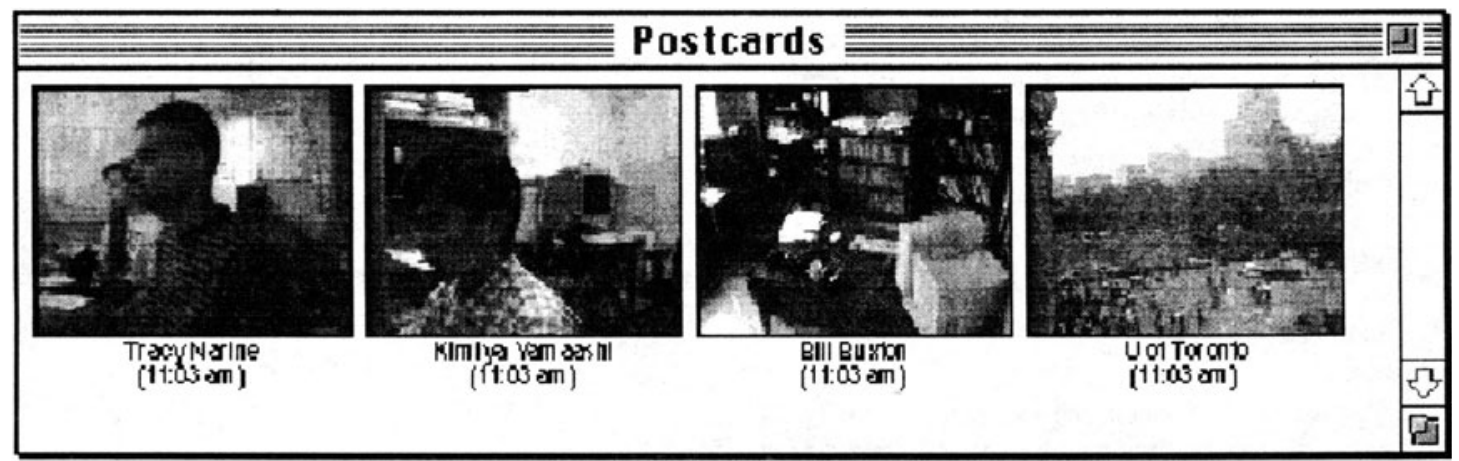

Figure 1: Postcards main screen 


\subsection{Group Organization}

The team's senior manager is extremely busy and travels frequently. A queue of people often form at his door when he is in town. When the senior manager is not available, the team's project manager guides the team's work. Three team members report directly to the project manager. The other team member works independently and reports to the senior manager. The team has one regularly scheduled meeting per week. Peripheral members of the study group do not meet regularly with the other members but do have informal spontaneous meetings with one or more of the team's members.

\section{MEASURING POSTCARDS USE}

Postcards usage data was collected for a total of three weeks. We logged user actions, distributed a questionnaire, conducted informal interviews with subjects and gathered E-mail comments.

The Postcards client logged the total time it was running, all user actions and the duration of any user requests. We logged the number of pictures that the users displayed, an indication of the formation of subgroups of communication. We also measured how many times the participants made use of the Sense and User Information options to provide support of our belief that Postcards provided the initial stimulus for a communication and provided appropriate support for enacting that stimulus.

The questionnaire we distributed to the eight participants in the study focused on their perceptions and memory of what they did when they initiated a communication with a co-worker. It also asked what strategies they used to find a co-worker and what sparked a communication to take place. Answers to these questions would examine the validity of our collaboration awareness claims. On a more practical note, we also wanted to know how users felt about the operation and features of the system and what items they thought would be useful to add to Postcards.

Informal interviews with each of the study's participants provided us with usage anecdotes plus a suggestion list for problems to fix. E-mail comments also gave us insights into problems users encountered with the system

\section{RESULTS}

The responses to our questionnaire were uniformly similar and provided evidence that all three forms of collaboration awareness were being used to facilitate communication. Participants in the study used Postcards heavily to support finding the window of opportunity for their intent to communicate. They used it less as a reminder to communicate (intent stimulus) but reported that Postcards contributed to increasing their familiarity with co-workers (intent comfort). Anecdotes of more personal expressions via Postcards suggest that users feel quite comfortable with each other, but we have no evidence that Postcards in any way fostered this familiarity.

We asked a series of questions on how group members used Postcards when they wished to contact another group member. Table 1 illustrates that users used Postcards for verifying the availability of a co-worker whenever they telephoned or visited a colleague especially if the person resides on another floor. Six of the eight users always checked Postcards before traveling to another floor and exactly half of the users always check Postcards before phoning others. The two users who never check Postcards when visiting someone on the same floor are close enough to hear and see the people they wish to visit.

\begin{tabular}{|l|c|c|c|}
\hline Question & Always & Sometimes & Never \\
\hline Before I do the following, I check Postcards: \\
\hline telephone & 4 & 4 & 0 \\
\hline visit on another floor & 6 & 2 & 0 \\
\hline make a same floor visit & 2 & 4 & 2 \\
\hline I wait for a new picture before: & 1 & 3 & 4 \\
\hline visiting that individual & 0 & 2 & 6 \\
\hline telephoning someone & \multicolumn{5}{|c|}{} \\
\hline The pictures remind me that I need to talk with the person \\
\hline about a work issue & 0 & 3 & 2 \\
\hline about a non-work isssue & 0 & 0 & 5 \\
\hline
\end{tabular}

Table 1: Use for making contact with co-workers 
Users usually did not wait for a picture to be updated before they telephoned or visited suggesting that they assumed that contact opportunity has remained the same since the last image capture. Our questionnaire also asked if the images prompted a communication to take place. Their responses indicated that this happened occasionally for work related issues but not for social exchanges. Although this suggests that Postcards is not used for intent stimulus, it is unlikely that users can accurately report this phenomena as Nesbitt and Wilson (1977) demonstrate in their classic paper. These answers indicate that users do not perceive that Postcards gives them any intent stimulus.

Intent opportunity was also supported by a question which asked what types of strategies people used when they wanted to make contact with a co-worker. Table 2 lists the responses to this question. The results indicate that all participants used Postcards daily for checking the contactability of others. Since Postcards was not an available strategy until its installation, this 100 percent adoption by all group members indicates the usefulness of this intent opportunity support that Postcards provides. Users did not report using the sensing function for setting up a future contact possibility. This is corroborated by the logged data and individual interviews. We believed that use of the sensing function would be related to Postcards provision of intent stimulus, but the lack of immediacy of a contact is already supported by the voice and E-mail media which are used more than sensing.

\begin{tabular}{|l|l|}
\hline Strategies for making Contact: & \\
\hline use Postcards sensing tool & 0.75 \\
\hline periodically check Postcards pictures & 3.00 \\
\hline continue to walk by their office & 1.13 \\
\hline leave voicemail with a request & 2.13 \\
\hline leaving an E-mail with a request & 1.88 \\
\hline leaving a note with a request & 0.88 \\
\hline $\begin{array}{l}\text { Meaning:0=never, } 1=\text { few times/month, } \\
\text { = few times/week and 3 = daily use. }\end{array}$ \\
\hline
\end{tabular}

Table 2: Strategies employed for finding a co-worker

We asked users to give their perception on changes that Postcards made to their work habits. On average, the results show increased intent opportunity. In particular, users reported less travel between floors because of Postcards and less frustration in finding their co-workers. They saw no increase in their informal meetings, telephone conversations, or E-mail exchanges. Users also indicated that they have a better sense about what is happening with their co-workers and what their co-workers' work pressures are. This was also reported anecdotally when one co-worker indicated that he saw that another colleague was very busy with meetings in his office. These results are shown in Table 3.

\begin{tabular}{|l|l|}
\hline Changes in work habits: & 1.88 \\
\hline informal meetings & 2.00 \\
\hline telephone conversations & 2.75 \\
\hline travelling from floor to floor & 2.13 \\
\hline writing notes to co-workers & 2.00 \\
\hline writing E-mail to co-workers & 2.63 \\
\hline frustration with finding co-workers & 1.50 \\
\hline knowing what is going on at work & 1.63 \\
\hline sense of other's work pressures & 2.00 \\
\hline going to lunch with co-workers & \\
\hline Meaning: 1=more, 2=same, 3=less
\end{tabular}

Table 3: Perceived changes in work habits

We also asked how Postcards was used and the results are shown in Table 4. Users readily used the system to find lunch and dinner companions and also to check for an intent opportunity. They also simply used the system to view their co-workers. We interpret this viewing as a form of intent comfort, that is, a building of familiarity with one's co-workers.

How Postcards is used daily:

\begin{tabular}{|c|c|}
\hline seeing who is avail. for lunch & 0.88 \\
\hline seeing if a colleage is avail. for a phone call & 1.63 \\
\hline seeing what a colleage is doing & 0.63 \\
\hline glancing at co-workers & 1.50 \\
\hline seeing if a colleage is avail. for a visit & 1.75 \\
\hline
\end{tabular}

Table 4: How Postcards is used daily

We also asked users if Postcards had increased their awareness of working in a group. Users responded to a five point Likert scale with $1=$ strongly agree, $2=$ agree, $3=$ neutral, $4=$ disagree and 5=strongly disagree. The average of the responses was 1.75 .

Most of our results are based on user's perceptions of how they use Postcards. The reliability of their responses is corroborated by $\log$ data on their use of the 
sensing and information functions which are quite low, as reported. The other results, however, are suspect until correlated with a behavior measure. The anecdotes about usage and the active user maintenance of the system suggest that Postcards' collaboration awareness is useful to the group. The user's responses to our queries of how it is useful fits our model of providing useful information for the three proposed types of precommunication planning.

\subsection{Postcards Usability}

The questionnaire also asked users to evaluate various features of Postcards. About half of the study group found the sound played before picture capture to be disruptive and annoying. Most of the members who did not like the sound recorded their own. One of the participants situated in an open-office environment complained that the sound annoyed surrounding workers. This problem ceased when the user recorded a quieter sound. Some users were uncomfortable with the picture being taken immediately after the warning sound. Consequently, a 2 second delay was added.

An important attribute of the system is the interval between subsequent snapshots. Within the study group. 4 out of 7 members were content with a 3 to 5 minute interval. The other 3 members wanted updates to be every 1 to 2 minutes. No-one requested a longer interval between snapshots.

\subsection{New Features}

There were several features that the users mentioned that they would like to see in a later release of the software. This included the ability to send out a standard set of messages to other users such as busy, not busy, lunch, in a meeting or on vacation. They were also interested in being able to send electronic Post-its to other users or to attach Post-its to their Postcard display. This would support a simple reminder system.

Another feature that was discussed several times throughout the duration of the experiment is the ability to immediately update any Postcards picture. We felt that supporting this functionality would infringe on the rights of users of the system. Especially in the case when any individual attempts to continuously update another's picture. In the current implementation, there is no method for a user to control accessibility of their picture. This type of functionality would be necessary before supporting instant updates of any individual's picture.

\section{ANECDOTAL USAGE}

The questionnaire asked users to list any anecdotes about how they or a colleague used the systems in ways that were unique or different than what was expected. We elicited this information because it often suggests design changes and because it provide some insight into how the system is being incorporated into the workplace and worklife.

Three anecdotes are of interest for these purposes. In one case, a team member put a stuffed animal in front of the Postcards camera whenever they was away from their office or desirous of privacy. The use of the animal for both purposes conveyed a confusing message to coworkers. However, its very ambiguity provided a privacy protection that Postcards had taken away. Colleagues could not know if the person was actually absent from their office or intensely working on a project. The stuffed animal message did not thwart any of the intents to contact because it clearly said that contact was not possible but was removed at other times when contact was possible.

Two users were also observed to be making faces (presumably at each other) but humorously shared with the entire work group. This suggests a high degree of comfortableness with other members of the work group since the "faces" remain displayed for four minutes.

If members of the study group forgot to tell visitors about Postcards, visitors were often "spooked" by the sound announcing the picture capture. The sound is supposed to sound like a camera shutter clicking but if heard out of context, it is difficult to guess what it was. This suggests another problem with the design of Postcards. Visitors have not agreed to have their images broadcast to others, yet by visiting a Postcards office, they are suddenly visible to the entire work group. The work group is also visible to them creating the effect of visiting a virtual open office (Li \& Mantei, 1992). Fortunately, the choice to limit the quality of the images also limits the invasiveness of visitor image capture. 


\section{CONCLUSIONS}

Overall, we have found that Postcards was being used by the co-located group, but not completely in the ways we anticipated. Its primary usage was that of managing the intent opportunity - seeing if an individual was available for contact. Its secondary usage was that of coworker observation which can be weakly interpreted as supporting intent comfort. We saw little evidence of intent stimulus. However, the group, although dispersed in the company, was not separated sufficiently so that other forms of intent stimulus were not already available. Indeed, it can be argued that because the group already had a communication network in place with tight links between all participants, that intent stimulus was not necessary and therefore not measurable. A different form of study would need to enacted, one in which communication links had fallen below a given threshold and were rejuvenated by the use of Postcards.

As a collaboration awareness tool, the Postcards usage demonstrates its simple effectivity in a co-located environment for coordinating communication. As such, it meets Hollan's criteria that a CSCW tool, to be used by both distant and local groups, must provide the same added value to both groups. Postcards appears to do this.

\section{ACKNOWLEDGMENTS}

Many thanks to those who participated in this study, Canada's National Science and Engineering Research Council, Alias/Wavefront Inc. and British Telecomm which helped fund this research. Also, we thank Xerox for providing us with the Portholes code. and the developers that have been associated with this project

\section{REFERENCES}

Buxton, W. (1995) Integrating the Periphery and Context: A New Taxonomy of Telematics, in Proc. GI'95 Graphics Interface Conference, ACM Press, 239-246.
Buxton, W. (1994) Metaphors that Keep us on the Periphery, Human Computer Interaction, 9, 1, 50-52. Dourish, P. and Bly, S. (1992) Portholes: Supporting Awareness in a Distributed Work Group, in Proc. CHI'92 Conf. on Human Factors in Computing Systems, ACM Press, 541-547.

Haythornthwaite, C., Wellman, B., and Mantei, M. (1995) Putting Computerized Communications in Perspective: Media Use and Work Relationships in a Research Group. Group Decision and Negotiation, 4, 3.

Hollan, J. and Stornetta, S. (1992) Beyond Being There, in Proc. CHI'92 Conf. on Human Factors in Computing Systems, ACM Press, 119-125.

Kraut, R. and Egido, C. (1988) Patterns of Contact and Communication in Scientific Research Collaboration, in Proc. CSCW'88 Conf. on Computer-Supported Collaborative Work, ACM Press, 1-11.

Li, J. and Mantei, M. (1992) Working Together Virtually, in Proc. GI'92 Graphics Interface Conf., 115-122.

Monge, P. R., Rothman, L. W., Eisenberg, E.M., Miller, K. L. and Kirste, K. K. (1985) The Dynamics of Organizational Proximity. Management Science, 31, 1129-1141.

Nisbett, R.E. and Wilson, T. D. (1977) Telling More than We can Know: Verbal Reports on Mental Processes. Psychological Review, 84, 231-259.

Root, R. (1988) Design of a Multi-Media Vehicle for Social Browsing, in Proc. CSCW'88 Conf. on Computer-Supported Cooperative Work, ACM Press, 25-38.

Scott, J. (1991) Social Network Analysis. London, Sage.

Short, J., Williams, E., and Christie, B. (1976) The Social Psychology of Telecommunications. London: John Wiley and Sons.

Tang, J. C., Isaacs, E. A. and Rua, M. (1994) Supporting Distributed Groups with a Montage of Lightweight Interactions, in Proc. CSCW'94 Conference on Computer-Supported Cooperative Work, ACM Press, 23-34.

Williams, E. (1977) Experimental Comparisons of Face-to-Face and Mediated Communication: A Review. Psychological Bulletin, 84, 963-976. 